\title{
Potential of FTIR spectroscopy in chemical characterization of Termitomyces Pellets
}

\author{
Rosy Agnes D'Souza, Nandkumar Mukund Kamat* \\ Department of Botany, Goa University, Taleigao, Goa, 403206, India.
}

\begin{tabular}{|c|c|}
\hline ARTICLE INFO & ABSTRACT \\
\hline $\begin{array}{l}\text { Article history: } \\
\text { Received on: 09/01/2017 } \\
\text { Accepted on: } 02 / 03 / 2017 \\
\text { Available online: } 14 / 08 / 2017\end{array}$ & $\begin{array}{l}\text { Potential of Fourier-Transform Infrared (FTIR) spectroscopy was assessed and Hierarchical Cluster Analysis } \\
\text { (HCA) was applied over entire range of spectra for determining characteristic chemical compositional } \\
\text { similarity of } 11 \text { different Termitomyces Heim strains using } 20 \text { days old pelletized dry biomass produced under } \\
\text { submerged shaken condition at } 28 \pm 1^{\circ} \mathrm{C} \text {. Four dominant spectral windows showing C-H, O-H stretching }\end{array}$ \\
\hline $\begin{array}{l}\text { Key words: } \\
\text { Termitomyces, FTIR, Hierarchical } \\
\text { Cluster, Chemometry, Spectral } \\
\text { windows, Pellet. }\end{array}$ & $\begin{array}{l}\text { region, amide I, amide II and polysaccharide regions were identified displaying characteristic variable bands } \\
\text { across species at } 3400-3200 \mathrm{~cm}^{-1}, 2900-2850 \mathrm{~cm}^{-1}, 2350-2215 \mathrm{~cm}^{-1}, 1750 \mathrm{~cm}^{-1}, 1658-1625 \mathrm{~cm}^{-1}, 1582-1547 \\
\mathrm{~cm}^{-1}, 1375-1315 \mathrm{~cm}^{-1} \text { and } 900-725 \mathrm{~cm}^{-1} \text {. The HCA dendrogram showed formation of two major clusters based } \\
\text { on their presumptive chemical similarity. }\end{array}$ \\
\hline
\end{tabular}

\section{INTRODUCTION}

The identification of fungi by traditional phenotypic methods and molecular methods requires special laboratory skills and expertise, besides being time consuming and expensive [1]. Fourier-transform infrared (FTIR) spectroscopy has been known to be a very promising method to characterize biological samples by their chemical composition and provides qualitative and quantitative estimates of lipids, polysaccharides, nucleic acids, proteins [2, 3]. FTIR spectrum is considered as a global "molecular fingerprint" which can be used for characterization, differentiation and identification of microorganisms [1] and has been widely applied for identification of bacteria [3-5], yeast, filamentous fungi $[6,7]$ and also some mushrooms [8-10]. Various fungal genera have been identified by using dry spores, fruit bodies or cultural biomass as source material for FTIR. These include Aspergillus [2], Mucor [11], Penicillium [2, 12], Memnoniella, Fusarium [12] and dermetophytes [13] and certain wood fungi [14], food spoilage fungi [15] and mushrooms genera such as Agaricus, Amanita, Lactarius, Macrolepiota and Pleurotus [8]. Fungal cell wall structure and chemical composition is found to be diverse from species to species and

\footnotetext{
* Corresponding Author

Nandkumar Mukund Kamat, Department of Botany, Goa University,

Taleigao, Goa, 403206, India.Email:nkamat@ unigoa.ac.in
}

thus characterization of fungi by their cell walls is generally thought to be very difficult [16]. Chitin, a polymer of the acetylated amino $\mathrm{N}$-Acetylglucosamine in which the subunits are linked by $\beta(1 \rightarrow 4)$-a glycosidic bond is a major chemical component of fungal cell walls. Other main fungal wall constituents are lipids, glycoproteins, cellulose, $\beta$ glucan, mannan, chitosan and other polysaccharides [16, 17]. Termitomyces Heim is most popular and highly priced edible mushroom genus in Africa and Asia. Termitomyces species are known to have high nutritive value $[18,19]$ and also contain novel neuritogenic cerebrosides $[20,21]$. However domestication of Termitomyces has failed due to its complex mutualistic nature with fungus growing termites Macrotermitinae [22] thus, requiring approaches like submerged fermentation. In order to standardize Termitomyces submerged fermentation process there is need to characterize its pellet biomass for future validation of its purity and chemical signature. Termitomyces pellets are known to represent 3D heterogeneity [23]. Also Termitomyces clypeatus pelletized biomass has also been used for metal biosorption of Chromium from waste water [24-27] thus indicating need to understand its chemical profiling across different species. Consistent with previous attempts to use FTIR spectroscopic technique for characterization of viable fungal biomass this work was aimed at its application to determine presence or absence of distinct chemical signatures from submerged growth conditions, aiding in chemical characterization of different Termitomyces species. 


\section{MATERIALS AND METHODS}

\subsection{Fungal Strains and Cultivation Conditions}

In all 11 pure mycelial cultures of Termitomyces were isolated from sterile context tissues of fresh fruit bodies of six species. The purity of these cultures was checked macro and microscopically [28-34]. These were T. albuminosus (TAL1, TAL2), T. striatus (TSTR), T. aurantiacus (TAUR), T. heimii (THE2), T. globulus (TGLO), and T. clypeatus (TCL1, TCL2, TCL3, TCL4, TCL5). These cultures were maintained on Malt Extract Agar $\left(20 \mathrm{~g} \mathrm{~L}^{-1}\right.$ Agar bacteriological grade; $20 \mathrm{~g} \mathrm{~L}^{-1}$ Malt extract powder, HiMedia) in slants at $28^{\circ} \mathrm{C}$ in Goa University Fungus Culture Collection (WFCC Reg. no. 946).

\subsection{Preparation of Fungal Pellets}

Ten plugs of $5 \mathrm{~mm}$ diameter each excised from old colonies growing on Czapek Dox Agar plates containing $5 \mathrm{~g} \mathrm{~L}^{-1}$ Sucrose, as carbon source for 6 days were transferred to flasks in triplicates which contained $100 \mathrm{ml}$ of Czapek Dox Solution with 5 $\mathrm{g} \mathrm{L}^{-1}$ Sucrose and incubated at $28 \pm 1^{\circ} \mathrm{C}$, pH 5.5, dark for 7 days at $150 \mathrm{rpm}$. The fungal biomass was obtained by centrifugation at $5000 \mathrm{rpm}$ for $20 \mathrm{~min}$ in sterile centrifuge tubes and washed thrice with sterile distilled water. The biomass was resuspended into 100 $\mathrm{ml}$ sterile distilled water in Erlenmeyer flasks containing 100 sterile glass beads of 3.5-4.5 mm diameter and kept for maceration on orbital shaker at $300 \mathrm{rpm}$ for $20 \mathrm{~min}$.

The fragmented mycelial suspensions, $1 \% \mathrm{v} / \mathrm{v}$, from biomass was added to flask with $100 \mathrm{ml}$ Czapek Dox liquid medium with pH 5.5 and incubated on shaker at $28 \pm 1^{\circ} \mathrm{C}$ in dark at $150 \mathrm{rpm}$ for 20 days.

\subsection{FTIR Analysis}

The pelletized biomass was washed with sterile distilled water and dried in an oven maintained at $75^{\circ} \mathrm{C}$ for $48 \mathrm{~h}$. Dried composite of whole pelletized biomass was macerated using mortar and pestle. Samples of $1 \mathrm{mg}$ were mixed with $100 \mathrm{mg}$ of spectroscopic grade $\mathrm{KBr}$, HiMedia. The FTIR spectra were determined between 4000 and $400 \mathrm{~cm}^{-1}$ using a Shimadzu IR Prestige 21 with the following parameters: Spectral resolution 4 $\mathrm{cm}^{-1}$, 40 scans $\mathrm{min}^{-1}$, encoding interval $1 \mathrm{~cm}^{-1}$, Happ-Genzel apodization and scanning speed $2.8 \mathrm{~mm} \mathrm{~s}^{-1}$.

\subsection{Multivariate Statistical Analysis}

These spectra were analyzed for signal processing procedure by smoothing on spectral second derivatives using Savitzky-Golay method with 9 points of window using Origin version 8 (OriginLab Corporation) graphing and analysis software [35] and the multivariate statistical analyses were performed using Hierarchical Cluster Analysis (HCA) using SYSTAT software version 13 (Systat Software Inc, Chicago, IL).

Cluster analysis easily classifies data into groups which helps to show similarities and is widely used for rapid differentiation and classification of spectral data of microorganisms [3].

\section{RESULTS AND DISCUSSION}

This is first report on application of FTIR for genus Termitomyces for following species T. albuminosus, $T$. striatus, $T$. aurantiacus, T. heimii, T. globulus and T. clypeatus. Most of the work reported in literature is done with natural fruitbodies and solid state cultural mat but rarely on pellet biomass produced by liquid submerged fermentation. Thus there are differences in metabolic cultures grown on solid and liquid cultures. Fig. 1 shows composite representation of FTIR spectra for 11 different Termitomyces strains belonging to six different species. Chemically significant regions of FTIR called spectral windows were identified which included fatty acid region dominated by $\mathrm{C}$ $\mathrm{H}\left(3450-2850 \mathrm{~cm}^{-1}\right)$; amide region dominated by $\mathrm{C}=\mathrm{O}$ amide $\mathrm{I}$ and $\mathrm{N}-\mathrm{H}$ amide II bands of proteins and peptides $(1800-1500 \mathrm{~cm}$ $\left.{ }^{1}\right)$; Mixed region (1500-1200 $\left.\mathrm{cm}^{-1}\right)$; polysaccharides region (1200$900 \mathrm{~cm}^{-1}$ ); true finger printing region (900 to $700 \mathrm{~cm}^{-1}$ ) [24, 3640]. Detailed FTIR bands assignments of characteristic infrared bands across Termitomyces species are shown in Table 1.

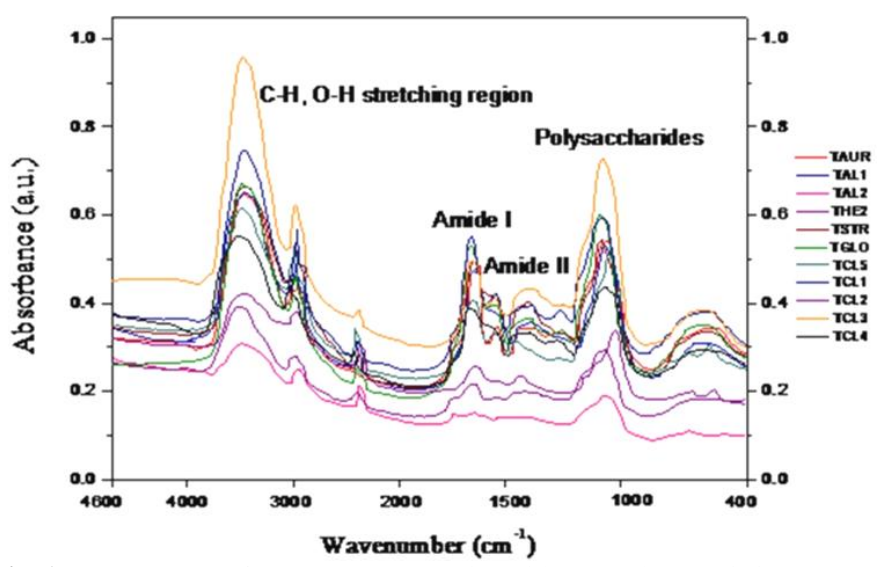

Fig. 1: FTIR spectra of Termitomyces species with some characteristic dominant spectral windows.

Table 1: Assignment of Infrared absorption bands for Termitomyces species [24, 37-40].

\begin{tabular}{ll}
\hline Frequency $\left(\mathbf{c m}^{-1}\right)$ & Band Assignment \\
\hline $3400-3200$ & $\mathrm{O}-\mathrm{H}$ stretching vibration of hydroxyl groups, \\
& Amine N-H stretching \\
$2900-2850$ & $\mathrm{CH}_{3}, \mathrm{CH}_{2}$ stretching \\
$2350-2215$ & $\mathrm{C} \equiv \mathrm{C}$ alkyne stretching \\
1750 & $\mathrm{C}=\mathrm{O}$ carbonyl stretching of esters \\
$1658-1625$ & Amide I, chitin \\
$1582,1550,1547$ & $\mathrm{~N}-\mathrm{H}$ bending -Amide II, chitosan \\
$1450-1425$ & O-H bending bending polysaccharide \\
$1375-1315$ & $\mathrm{O}-\mathrm{H}$ bending polysaccharide, Amide III \\
$1250-1025$ & $\mathrm{C}-\mathrm{O}$ bond, $\quad$ p $\quad(1 \rightarrow 3) \quad$ glucan, cell wall \\
& polysaccharide \\
900 & $\beta(1 \rightarrow 6)$ glucan, Finger print region \\
$810-725$ & $-\mathrm{N}-\mathrm{H}$ wag, Finger print region \\
\hline
\end{tabular}

FTIR spectral bands of pellet biomass were found to be contributing characters of three physiological different regions. Central pellet zone (chemical zone-I) consisting of less oxygen tension, limited energy metabolism leading to autolysis, cell wall degeneration, vacuolation and also secondary metabolite 
production [41, 42]. Intermediate pellet zone (chemical zone-II) is with less or partial degeneration of chitin microfibrils, cell wall glycoproteins and beginning of some secondary metabolite production. Barberel and Walker [41] have modified the zones of hypothetical fungal pellet from Trinci [43]. According to Barry and Williams [42] and Bizukojc and Ladakowicz [44] the illustrations of pellet morphology indicates the densely stained central pellet zone as inactive layer. Pirt [45] claimed that when the pellet diameter exceeds certain value, the growth is limited to a certain thickness at peripheral zone and it depends on diffusion coefficient and nutrient availability. Outer pellet zone (chemical zone-III) known as active layer consists of high oxygen availability and nutrient uptake indicating fresh cell wall material [42], de novo chitin, chitosan biosynthesis, no secondary metabolite production [46] and healthy cytoplasm. The vacuolated cells are metabolically different than the actively growing apical and subapical cells and they are known for the production of secondary metabolites [47]. Thus it is assumed that the spectral chemotypes of Termitomyces pellets could be directly proportional to the contributions from all these three pellet zones.

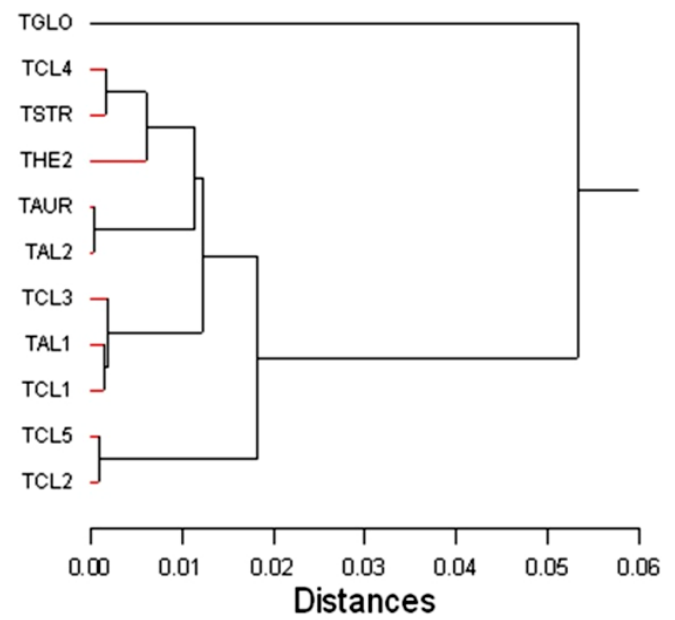

Fig. 2: The dendrogram indicates the difference between the species of Termitomyces.

Fig. 2 shows the dendrogram calculated by cluster analysis, where the separation shows clear heterogeneity distances among Termitomyces species forming two cluster groups that occur about the same horizontal distance of 0.053 . TGLO forms outlier to the two sister clade resolved at distance 0.018. Different species of Termitomyces showed heterogeneity below 0.06 (Table 2 ). The distance measures were comparably lower in TAUR, TAL1, TAL2, TCL1, TCL2, TCL4, TCL5 and TSTR indicating less heterogeneity than THE2, TAUR and TGLO. The FTIR spectral chemometrics of different Termitomyces species showed sub grouping with other species may be due to heterogeneity of chemical components in different pellet zones. Grouping various strains to form clusters representing species or genera based on taxonomical classification is not always satisfactory by using physiological and morphological characters [48, 49]. The chemical heterogeneity between these species may be affected by the geographic origin, morphology, physiology of culture and ability for metabolite production. The FTIR spectral cluster analysis helped in grouping chemically related species together indicating strains could be grouped based on their comparably higher similarity in metabolite production [2]. According to previous reports by Kummerle et al., [50] and Lecellier et al., [1] HCA of spectra from different species of the same genus and also strains from the same species generally did not cluster together. Thus we can conclude that the use of FTIR spectroscopy for taxonomic purposes is limited but it does not prevent it from being a powerful identification system based on spectral chemotypes [50].

Table 2: Distance Metric - Pearson Correlation Coefficient Ward Minimum Variance Method.

\begin{tabular}{lccc}
\hline \multicolumn{2}{c}{ Cluster Joining } & At Distance & No. of Members \\
\cline { 2 - 4 } TAUR & TAL2 & $\mathbf{0 . 0 0 0}$ & $\mathbf{2}$ \\
\hline TCL5 & TCL2 & 0.001 & 2 \\
TCL1 & TAL1 & 0.001 & 2 \\
TCL4 & TSTR & 0.002 & 2 \\
TCL3 & TCL1 & 0.002 & 3 \\
TCL4 & THE2 & 0.006 & 3 \\
TAUR & TCL4 & 0.011 & 5 \\
TCL3 & TAUR & 0.012 & 8 \\
TCL5 & TCL3 & 0.018 & 10 \\
TGLO & TCL5 & 0.053 & 11 \\
\hline
\end{tabular}

\section{CONCLUSION}

The FTIR spectroscopic technique coupled with chemometric methods found principal advantage in understanding chemotypic similarity between different Termitomyces species in 3-D pelletized form but may not be helpful to classify strains based on their taxonomic ranking.

\section{ACKNOWLEDGEMENTS}

The authors would like to acknowledge the support by UGC-SAP Phase-II Programme for support, Goa University Fungus Culture Collection \& Research Unit (GUFCCRU) for cultures. For the FTIR spectroscopy related work we would like to thank the Chemistry Department of Goa University. First author would also like to thank for DST-INSPIRE Fellowship for providing financial support.

Conflict of Interests: There are no conflicts of interest.

\section{REFERENCES}

1. Lecellier A, Mounier J, Gaydou V, Castrec L, Barbier G, Ablain W, Manfait M, Toubas D, Sockalingum GD. Differentiation and identification of filamentous fungi by high-throughput FTIR spectroscopic analysis of mycelia. International Journal of Food Microbiology. 2014; 168:32-41.

2. Fischer G, Braun S, Thissen R, Dott W. FT-IR spectroscopy as a tool for rapid identification and intra-species characterization of airborne filamentous fungi. Journal of Microbiological Methods. 2006; 64(1):63-77.

3. Aguiar JC, Mittmann J, Ferreira I, Ferreira-Strixino J, Raniero L. Differentiation of Leishmania species by FT-IR spectroscopy. Spectrochimica Acta Part A: Molecular and Biomolecular Spectroscopy. 2015; 142:80-85. 
4. Amiel C, Mariey L, Curk-Daubié MC, Pichon P, Travert J. Potentiality of Fourier transform infrared spectroscopy (FTIR) for discrimination and identification of dairy lactic acid bacteria. Le Lait. 2000; 80(4):445-459.

5. Johler S, Stephan R, Althaus D, Ehling-Schulz M, Grunert T. Highresolution subtyping of Staphylococcus aureus strains by means of Fourier-transform infrared spectroscopy. Systematic and Applied Microbiology. 2016; 39(3):189-194.

6. Santos C, Fraga ME, Kozakiewicz Z, Lima N. Fourier transform infrared as a powerful technique for the identification and characterization of filamentous fungi and yeasts. Research in Microbiology. 2010; 161(2):168-175.

7. Lecellier A, Gaydou V, Mounier J, Hermet A, Castrec L, Barbier G, Ablain W, Manfait M, Toubas D, Sockalingum GD. Implementation of an FTIR spectral library of 486 filamentous fungi strains for rapid identification of molds. Food Microbiology. 2015; 45:126-134.

8. Mohacek-Grosev V, Bozac R, Puppels GJ. Vibrational spectroscopic characterization of wild growing mushrooms and toadstools. Spectrochimica Acta Part A: Molecular and Biomolecular Spectroscopy. 2001; 57(14):2815-2829.

9. Liu G, Liu JH, Yang AM, Dong Q, Song DS. Identification of edible mushrooms by Fourier transform infrared spectroscopy. Guang pu xue yu guang pu fen xi= Guang pu. 2004; 24(8):941-945.

10. Gonzaga ML, Ricardo NM, Heatley F, Soares SD. Isolation and characterization of polysaccharides from Agaricus blazei Murill. Carbohydrate Polymers. 2005; 60(1):43-49.

11. Shapaval V, Moretro T, Suso HP, Asli AW, Schmitt J, Lillehaug D, Martens H, Bocker U, Kohler A. A high-throughput microcultivation protocol for FTIR spectroscopic characterization and identification of fungi. Journal of Biophotonics. 2010; 3(8-9): 512-521.

12. Erukhimovitch V, Pavlov V, Talyshinsky M, Souprun Y, Huleihel M. FTIR microscopy as a method for identification of bacterial and fungal infections. Journal of Pharmaceutical and Biomedical Analysis. 2005; 37(5):1105-1108.

13. Bastert J, Korting HC, Traenkle P, Schmalreck AF. Identification of dermatophytes by Fourier transform infrared spectroscopy (FT-IR). Mycoses. 1999; 42(9-10):525-528.

14. Naumann A, Navarro-González M, Peddireddi S, Kües U, Polle A. Fourier transform infrared microscopy and imaging: detection of fungi in wood. Fungal Genetics and Biology. 2005; 42(10): 829-835.

15. Shapaval V, Schmitt J, Moretro T, Suso HP, Skaar I, Asli AW, Lillehaug D, Kohler A. Characterization of food spoilage fungi by FTIR spectroscopy. Journal of Applied Microbiology. 2013; 114(3):788-796.

16. Edwards HG, Russell NC, Weinstein R, Wynn-Williams D. Fourier transform Raman spectroscopic study of fungi. Journal of Raman Spectroscopy. 1995; 26(8-9):911-916.

17. Das SK, Das AR, Guha AK. Structural and nanomechanical properties of Termitomyces clypeatus cell wall and its interaction with chromium (VI). The Journal of Physical Chemistry B. 2009; 113(5):1485-1492.

18. Kansci G, Mossebo DC, Selatsa AB, Fotso M. Nutrient content of some mushroom species of the genus Termitomyces consumed in Cameroon. Molecular Nutrition and Food Research. 2003; 47(3):213216.

19. Pahlevanlo A. Diversity nutritional value and bioactive principles from Termitomyces species of Kodagu region in Karnataka. Doctoral Thesis at Department of Microbiology, University of Mysore. 2013. [cited 2017 March 4]. Available from http://ir.inflibnet.ac.in:8080/jspui/handle/10603/72039.

20. Qi J, Ojika M, Sakagami Y. Neuritogenic cerebrosides from an edible Chinese mushroom. Part 2: Structures of two additional termitomycesphins and activity enhancement of an inactive cerebroside by hydroxylation. Bioorganic and Medicinal Chemistry. 2001; 9(8):2171-2177.

21. Choi JH, Maeda K, Hirai H, Harada E, Kawade M, Qi J, Ojika M, Kawagishi H. Novel Cerebroside, Termitomycesphin I, from the Mushroom, Termitomyces titanicus. Bioscience, Biotechnology, and Biochemistry. 2012; 76(7):1407-1409.
22. Olila D, Kyeyune G, Kabasa JD, Kisovi L, Munishi PKT Assessment of potential for domestication of Termitomyces microcarpus: An indigenous edible and medicinal mushroom from the lake Victoria Basin. Agricultural Journal. 2007; 2(5):627-631.

23. D'Souza RA, Kamat NM. Importance of understanding pellelization in Termitomyces Heim species for potential applications to produce edible nutritious mycoprotein. Presented at $8^{\text {th }}$ International Conference on Mushroom Biology and Mushroom Products, 19-22 $2^{\text {th }}$ November 2014 at NASC complex, New Delhi. [cited 2017 March 4] Available from http://f1000.com/posters/browse/summary/1097335.

24. Das SK, Guha AK. Biosorption of chromium by Termitomyces clypeatus. Colloids and Surfaces B: Biointerfaces. 2007; 60(1):46-54.

25. Ramrakhiani L, Majumder R, Khowala S. Removal of hexavalent chromium by heat inactivated fungal biomass of Termitomyces clypeatus: Surface characterization and mechanism of biosorption. Chemical Engineering Journal. 2011; 171(3):1060-1068.

26. Ramrakhiani $L$ and Khowala, S. Effect of pretreatment on hexavalent chromium biosorption and multimetal biosorption efficiency of Termitomyces clypeatus biomass. International Journal of Integrative Sciences, Innovation and Technology. 2012; 1:7-15.

27. Fathima A, Aravindhan R, Rao JR, Nair BU. Biomass of Termitomyces clypeatus for chromium (III) removal from chrome tanning wastewater. Clean Technologies and Environmental Policy. $2015 ; 17(2): 541-547$.

28. Heim R. Termites et Champignons. Boube'e: Paris. 1977.

29. Morris B. Notes on the genus Termitomyces Heim in Malawi. The Society of Malawi Journal. 1986; 40-49.

30. Botha WJ, Eicker A. Cultural studies on the genus Termitomyces in South Africa. I. Macro- and microscopic characters of basidiome context cultures. Mycological Research. 1991; 95(4):435-443.

31. Pegler DN, Vanhaecke M. Termitomyces of Southeast Asia. Kew Bulletin. 1994, p. 717-736.

32. Tibuhwa DD, Kivaisi AK, Magingo FSS. Utility of the macromicromorphological characteristics used in classifying the species of Termitomyces. Tanzania Journal of Science. 2010; 36(1).

33. Tibuhwa DD. Termitomyces Species from Tanzania, Their Cultural Properties and Unequalled Basidiospores. Journal of Biology and Life Science. 2012; 3(1).

34. Karun NC, Sridhar KR. Occurrence and distribution of Termitomyces (Basidiomycota, Agaricales) in the Western Ghats and on the west coast of India. Czech Mycology. 2013; 65(2):233-254.

35. Savitzky A, Golay MJ. Smoothing and differentiation of data by simplified least squares procedures. Analytical Chemistry. 1964; 36(8):1627-1639.

36. Dziuba B, Babuchowski A, Nałęcz D, Niklewicz M. Identification of lactic acid bacteria using FTIR spectroscopy and cluster analysis. International Dairy Journal. 2007; 17(3):183-189.

37. Zhu Y, Tan AT. Chemometric Feature Selection and Classification of Ganoderma lucidum Spores and Fruiting Body Using ATR-FTIR Spectroscopy. American Journal of Analytical Chemistry. 2015; 6(10):830-840.

38. Szeghalmi A, Kaminskyj S. Gough KM. A synchrotron FTIR microspectroscopy investigation of fungal hyphae grown under optimal and stressed conditions. Analytical and Bioanalytical Chemistry. 2007; 387(5):1779-1789.

39. Rinaudo $M$, Chitin and chitosan: properties and applications. Progress in Polymer Science. 2006; 31(7):603-632.

40. Di Mario F, Rapana P, Tomati U, Galli E. Chitin and chitosan from Basidiomycetes. International Journal of Biological Macromolecules. 2008; 43(1):8-12.

41. Barberel SI, Walker JR. The effect of aeration upon the secondary metabolism of microorganisms. Biotechnology and Genetic Engineering Reviews. 2000; 17(1):281-326.

42. Barry DJ, Williams GA. Microscopic characterisation of filamentous microbes: towards fully automated morphological quantification through image analysis. Journal of Microscopy. 2011; 244(1):1-20.

43. Trinci AP. Kinetics of the growth of mycelial pellets of Aspergillus nidulans. Archives of Microbiology. 1970; 73(4):353-367. 
44. Bizukojc M, Ledakowicz S. The morphological and physiological evolution of Aspergillus terreus mycelium in the submerged culture and its relation to the formation of secondary metabolites. World Journal of Microbiology and Biotechnology. 2010; 26(1):41-54.

45. Pirt SJ. A theory of the mode of growth of fungi in the form of pellets in submerged culture. Proceedings of the Royal Society of London B: Biological Sciences. 1966; 166(1004):369-373.

46. Calvo AM, Wilson RA, Bok JW, Keller NP. Relationship between secondary metabolism and fungal development. Microbiology and Molecular Biology Reviews. 2002; 66(3):447-459.

47. Cho YJ, Hwang HJ, Kim SW, Song CH, Yun JW. Effect of carbon source and aeration rate on broth rheology and fungal morphology during red pigment production by Paecilomyces sinclairii in a batch bioreactor. Journal of Biotechnology. 2002; 95(1):13-23.

48. Welthagen JJ, Viljoen BC. The value of certain chemotaxonomic methods in the identification of food related yeasts. Food Microbiology. 1997; 14(3):231-245.
49. Mariey L, Signolle JP, Amiel C, Travert J. Discrimination, classification, identification of microorganisms using FTIR spectroscopy and chemometrics. Vibrational Spectroscopy. 2001; 26(2):151-159.

50. Kümmerle M, Scherer S, Seiler H. Rapid and reliable identification of food-borne yeasts by Fourier-transform infrared spectroscopy. Applied and Environmental Microbiology. 1998; 64(6):2207-2214.

\section{How to cite this article:}

D'Souza RA, Kamat NM. Potential of FTIR spectroscopy in chemical characterization of Termitomyces Pellets. J App Biol Biotech. 2017; 5 (04): 080-084. DOI: 10.7324/JABB.2017.50412 